\title{
The Influence of Knowledge Management on Learning in Government Organisations
}

\author{
Mohamed Buheji1', Said Al-Hasan², Brychan Thomas², Denis Melle ${ }^{3}$ \\ ${ }^{1}$ University of Bahrain, Zallaq, Bahrain \\ ${ }^{2}$ University of South Wales Business School, Pontypridd, UK \\ ${ }^{3}$ France Business School, Brest, France \\ Email: buhejim@gmail.com, said.alhasan1@southwales.ac.uk, brychan.thomas@southwales.ac.uk, \\ denis.melle@france-bs.com
}

Received 2 October 2014; revised 5 November 2014; accepted 17 November 2014

Copyright (C) 2014 by authors and Scientific Research Publishing Inc.

This work is licensed under the Creative Commons Attribution International License (CC BY). http://creativecommons.org/licenses/by/4.0/

(c) (;) Open Access

\section{Abstract}

There has been a tendency for government organizations to become competitive due to instability in modern economies. Accordingly, Knowledge Management (KM) has been rapidly growing in the past decade as a source of influence on organisational development practices. In the past decade research approaches largely failed to show the importance of KM initiatives in creating synergy with other initiatives to an extent that would lead towards organizational competitiveness. This paper investigates whether KM holistically influences organisational learning, specifically in the context of the government sector. In order to understand the relationships between KM and organisational learning identified in the literature and increasingly used in practice, a quantitative survey approach was undertaken using a series of researcher-developed scales. Based on the literature review Organisational Learning (OL) was identified to be important in relation to $\mathrm{KM}$, and a conceptual framework was designed to test the concept of the holistic influence of KM on organisational learning. Some 625 valid responses were collected from top and middle management from 54 government organizations in the Kingdom of Bahrain, and the model was statistically tested according to the research hypotheses by regression analysis then Structural Equation Modelling (SEM). The results reveal strong and significant correlations amongst organisational development practices. Even though the holistic influence of the model could not be confirmed, findings show positive KM influence on organisational development practices, thus KM is an essential factor for government organisations. As well as illustrating KM as an important source of influence, this study establishes a new direction that helps to integrate all governmental organisations' initiatives in relevance to organisation development practice leading to better competitiveness. The research makes a novel contribution since it increases the probability of a holistic approach model that brings support for decision makers to enhance overall government organizations' competitiveness. The scale developed for the model tested can be generalised and used as a self assessment tool for organisational practices in KM. The work sets a baseline for KM practices in 
the Government of Bahrain and similar GCC Governments that can act as a reference for researchers on KM, learning and competitiveness in emerging economies. The model needs further investigation in future research to explore the missing variables to make it "fit for purpose". This concept of a holistic model needs to be further subjected to empirical investigation to explore its viability. The major limitation of this research is because it has addressed only the government sector in one country.

\section{Keywords}

Knowledge, Management, Government, Organisations, Learning

\section{Introduction}

Rapid changes in government services over the past two decades have attracted many researchers to the area of knowledge management (KM) and have stimulated interest in measuring and focusing on the need to improve government performance through different organisational development approaches. Many governments are trying to understand the world competitiveness, where competitiveness frameworks in governments and governmental organisations are more and more linked with characteristics of ability to maintain high quality level of services, ability to manage risks and ability to have the sense of accountability towards the future [1]-[3]. Governmental organizations (GOs) therefore are required more than ever today to preserve the quality of life and to fully exploit their potential so that they can attain, maintain and/or sustain nations' and peoples' prosperity.

Despite the increasing notion among researchers and practitioners about knowledge management's role and how it can be a practice that would support different organisational capabilities; it has yet to be investigated in the public sector of developing countries [3]-[5]. However, most government organisations today are not specifically structured for the application of KM concepts and initiatives needed for efficient public service-delivery coupled with global challenges in the knowledge-based economy which have motivated some governments such as the United Kingdom, Canada and Australia to consider KM implementation seriously [6]. Zhi-ze and Shuang-liang [7] reflected on how KM initiatives research can rarely be found in relevance to government process reengineering. Therefore, several countries infer that government organisations need to develop their capacity for the exclusive production and provision of knowledge to meet the constant demands and reform that would need to be achieved through organisational services development as originally discussed by Osborne and Gaebler [8]. Government organizations, with their diversified and growing functions need more than ever to see what triggers their organisational success and efficiency in their services which yet remains a challenge. The economic performance of a country depends on government organisations' competitiveness since they are the major employer and provider of services that directly influence the economy through economic policy and support which affects both the cost of inputs and social services [9]. To be successful in the new economy, organisations need to be capable of innovating and adopting far more quickly and effectively than their counterparts [10].

Research reported in this paper is based on the rationale that current frameworks do not provide clear, holistic, integrated guidance between KM and the prevalent organisational development practice of organisation learning [11]. Current research of KM influence and its relations does not utilise the benefits of integrating organisational development initiatives towards better organisational competitiveness [12]. Therefore, it is not clear which business parameters, in relevance to practices, are affected by KM's presence and to what extent such practice influence the other development practices that government organizations need more and more today.

The aim of this study is to investigate understanding towards the utilization of governments' initiatives and specifically KM programmes. This can be achieved by studying and defining the perceived links between the major enablers of KM practices and the major prevalent organisational development practice of learning. There is a need to study the effect of KM as an independent variable in GOs on the specific dependent variables. To achieve this aim, the following constitutes the key objectives of the research paper:

Objective 1: To develop an initial conceptual model for examining the holistic influence between knowledge management practices and organisational learning based on examination of the literature gaps in the body of 
knowledge.

Objective 2: To empirically text the relationship between KM and OL in the government organisation context.

Objective 3: To investigate and provide an understanding of how KM practices may contribute holistically to the organisation development practices that comprise the dimensions of organisational learning in the context of governmental organisations.

\section{Literature Review}

\subsection{KM Influence on Government Organizations and Their Initiatives}

Rusly et al. [13] have shown that KM effectiveness could be highly enhanced by cultural change readiness. Aranda and Fernandez [14] argue that most research on government performance today tends to focus on measuring the indicators of such performance, and analysing the source of the problem, rather than identifying the practices that would enable government organisations to have sustainable and competitive services. Understanding KM and its specific related government organization development practices are vital in developing and designing effective future programmes and services [15]. Taking this into account along with the external society dependency seen in the GO's sector, the literature was reviewed and analysed with consideration of challenges that might be faced in implementing $\mathrm{KM}$ and its relevant practices in this context. Understanding the processes of KM practices would benefit governmental sector since KM is more related to context-specific characteristics than just a transformation of facts.

Sharing is believed to take place only when there is trust and where there is a shared feeling of ownership of goals where tendency to share is based on the kind of interpersonal and social relationships within organizational teams [16]. Gorry [17] has shown how the proper sharing of knowledge between different government organizations enhanced staff services; giving an example of the influence of knowledge sharing in social services, education, health care and therefore the overall economy. McAdam and O’Dell [18] have proposed that the active exchange of knowledge both in private and public organisations led to improved quality, efficiency, management learning, products and services, and reduced operating cost. Thus the presence of knowledge is believed to be a source of business benefits such as a competitive advantage, minimization of costs, improved quality, responsiveness, or improved service to customers due to the systematic and interdisciplinary approach of knowledge management [19]. Recently, Zhi-ze and Shuang-liang [7] have shown that effective KM initiatives reduce the internal cost of management and service through re-engineering government processes that would enhance efficiency and improve the service for its citizens. However, these business benefits are not clearly seen within the government organisation culture where it is believed that complex government policies create basic challenges that prevent smooth and active exchange of knowledge from even effectively transferring tacit knowledge within it [3] [20]. Handzic [21] emphasises that even the GO's complex interactions influences the knowledge stocks of the organisation. Three studies on the Malaysian government showed a need for knowledge sharing practices, after knowledge economy strategy that was set ten years ago [10] [22]. Another work in Pakistan GO's recently carried by Abbass et al. [23] revealed a significant high relationship between the complexity of the government organisation practices and KM practices. Therefore, KM influence in government organizations, is argued by Abbass et al. [23], if suitably initiated by KM strategies would lead to better organisational performance. Chawla and Joshi [1] reflected the importance of KM by highlighting the Indian GO's role in setting up and facilitating economic growth in more than 51 percent of the equity in any organisation in the country. When compared to leading South East Asian countries for example Malaysia and Singapore's experience, GOs in the Gulf Cooperation Council (GCC) region are acknowledged to be lagging in creating KM suitable practices [5] [24] [25]. When compared to the clear Knowledge-based Economy Strategic Master Plans that the Malaysian government enjoy; the lack of common KM agreed goals in the GCC government sector severely hinders the effective implementation of any coming KM initiatives in such organizations [4].

$\mathrm{KM}$ in government organisations still possesses challenges that are different from the private sector due to the typical hierarchical and bureaucratic nature of GO's that makes sharing of knowledge difficult [26]-[28]. Al Gore (the ex-Vice president of United State of America) practically addressed the need for rapid change in the practices of KM in the government organisation, and as a result, the USA today has many local government programmes trying to create GOs that facilitate KM practices [29]. The empirical work collected from administrative and senior officers of 28 ministries located in Malaysia supports the notion that KM practices at the organizational level are a prerequisite for successful organizational performance [22]. Yet, there is still a lack of 
empirical evidence on how KM would be an effective tool for transforming relatively uncompetitive public sector organisations to more competitive entities.

\subsection{KM Influence on Organisational Learning}

Organisational Learning (OL) is seen as the ability of the organisation to learn from others and from within, which as Senge [30] has argued, could have a significant influence on how knowledge is transferred. Organisational learning implies both: being aware of the need for different levels of learning, and the storing of knowledge in the organisation. OL represent the capacity to change, through continuous improvement that is based on lessons learned from mistakes and learning from best practices [31]. OL is argued to be the source of organisational capability that can enhance the areas of experimentation, risk taking, external environment interaction and participative decision-making that lead to better organisational dialogue [10]. Chawla and Joshi [1] note that even the KM best practices can create OL for improving governmental organisation performance.

Recently, Venkitachalam and Busch [32] and Lee et al. [33] showed how tacit know-how account for an organization's learning capability and how it is critical to certain organizational roles than others. Firestone and McElroy [34] were the earliest to argue the possibility of integrating KM and OL as they believed that the difference between the two disciplines is shown to be complementary and to have a close relationship. Disciplines as organizational innovation, integrity, accountability, and risk management all seem to be effected if the relation between both KM and OL is clearly set [34] [35]. Certain authors proposed that the definition of OL has a clear relation on the wider use of $\mathrm{KM}$, that makes them both a main source of acceleration in the rate of change in the learning economy where the capability to learn becomes more important than given sets of specific capabilities [36]. KM and OL are believed to be linked to the satisfaction and the encouragement for learning practices as a result of organisation development [37]. Even though literature does not clearly distinguish between $\mathrm{KM}$ and $\mathrm{OL}$, OL is argued as the process to facilitate knowledge sharing and establishes continuous learning process within an organisation [38]. Therefore Basadur and Gelade [39] argued that the current concepts of KM and OL can improve organisational effectiveness through grasping opportunities that lead to better enhancement of human capital, innovation, social and organisational capital [12] [40] [41]. The cyclical development of OL caused by KM gives strength for the strategic role of the KM holistic and comprehensive model [42]. However, both OL and KM practices require a culture of trust and cooperation in order to play a role in the organisation ability towards organisational innovation (OI) or organisational competitiveness (OC) [43]-[45]. OL occurs when KM in one part of an organisation is transferred effectively to other parts and used to solve problems or to provide new and creative insights [46] [47]. Eskildsen et al. [48] found that OL and organisational excellence (OE) have similar strength on each other. While, the "learn and contribute" concept is considered the most challenging and vital step that can lead to OI and OC later [44]. Therefore, it is believed that KM can influence the OL strategy in sequence of getting the information or the knowledge, using it, learning more and then contributing again [18].

$\mathrm{KM}$ is argued to have a role in assisting employees in creating and using knowledge; establishing appropriate networks through engaging in double-loop learning along with network practices, that ease the complexity of the OL processes, and which helps to overcome the difficulty of unlearning [49] [50]. Therefore, KM helps organizations to establish their ability to learn and adapt to the fast changing competitive global environment through establishing internal processes that help convert learning and capital-based resources into desired outputs [51] [47]. Without certain KM practices, it has been argued that organisations cannot develop personal or group learning abilities [11]. Liao and Wu [11] proposed that OL gradually helps establish managerial commitment, systems perspective, openness and experimentation, knowledge transfer and integration. Knowledge acquisition, for example, has been proposed to have both direct and indirect influence on organisational learning and excellence practices [15].

The literature shows that KM initiatives, when established within organizational commitment, including provision for i.e. a learning climate this is believed to be effective in developing learning organization capacity [52] [53]. OL is found to resonate and develop in a dynamic process where knowledge moves along the different levels of action, going from an individual to a group level, and then to the organisational level and back again [54] [42]. This relationship between KM and OL is therefore believed to be as the hook adopting new habits and beliefs that would facilitate the transition from a reactive attitude, characterized by a slow adaptation to change, to a proactive attitude that anticipates modifications [39] [55]. 


\section{Research Methodology}

Research objectives were studied with reference to existing related frameworks and hence the development of a conceptual framework that defines and justifies the expected links between the prevalent organisational development concepts, in the context of governmental organizations using Dooley's [56] methods as a guide.

The research was undertaken systematically and a research methodology planned with reference to both the research objectives and questions. The hypothesis in this study was examined through both the screening and main survey following a data collection plan. The scale developed for the main survey followed the previous work to measure the influence of KM on other specified organisational development variables [4] [5] [25] [44] [57]-[59]. The research design highlighted that clear measurement scale of organisational development practices concepts (i.e. KM and OL) needed to be used in relevance to the context of governmental organisations.

It is believed by Al-Alawi et al. [5] that cultural influence on KM is quite significant; however it is quite common across all GOs, and the researchers consider a uniformity of culture acceptance. Therefore, the target sample was drawn from among the upper middle and the top management in all fifty four government and semi-government organisations in the Kingdom of Bahrain [60]. The main instrument targets to measure decision makers' perception on KM influences and specifically in the context of government organizations. For the second objective a regression model was developed, followed by Confirmatory Factor Analysis (CFA) with an in-depth rigorous hypotheses testing and model fit testing to see how all relations together would lead KM towards influencing the organization to being more competitive.

$\mathrm{KM}$ in order to sustain, it creates a cycle of continuous Organizational Learning (OL) that emanates into different types of practices [15] [61]. From the literature review, KM will affect OL positively and creatively due to enhancing the knowledge process capabilities that create, transfer, and use knowledge [62]. KM processes as per Maden [35] can mediate between KM infrastructure (i.e. collaboration, learning culture, and IT support) and OL. Therefore, in order to transform GOs into OL, they need a specific climate and this would lead to KM practices. Aside from this, most of the research reviewed and even the latest ones debate that the presence of the KM practices would lead to this learning climate [1] [63]. The relation between KM and OL has been reviewed in recent research studies, however the literature still shows paucity in this area of GOs again. This research therefore proposes the following hypothesis to be explored in the context of this study:

$\mathrm{H}$ : Knowledge management is positively associated with Organisational Learning (OL).

This hypothesis addresses both the framework testing and development besides the first objective. In order to bring the necessary research components into a generalised model, careful consideration of knowledge outcomes from the literature projections and impact of relationships was established. The conceptual framework (Figure 1) moves the research towards connecting the relationships between different concepts that would establish evidence to support the need for the research question "What is the holistic relationship between KM and OL?", which needs to be addressed through a model to be tested (Figure 2). The conceptual framework was evaluated for completeness and unity for being comprehensive in reflecting the dependent and independent variables. Therefore, the proposed framework shows the linkages and influence flow of KM over the identified organisation developments reflecting the established relations in a comprehensive process. The next step is to fully operationalise the conceptual framework.

In order to gain an understanding of the recursive ability of the KM influence on development practice (OL); the hypothesis is set to derive the main components of the framework thus addressing the possibility of the positive relation with KM. Since the primary research focus is on the holistic relation between KM practices and organisational learning development practices, the significance of this relation needs to be studied in detail. The framework considered in Figure 1 is established to enable the KM influence on different parameters in the con-

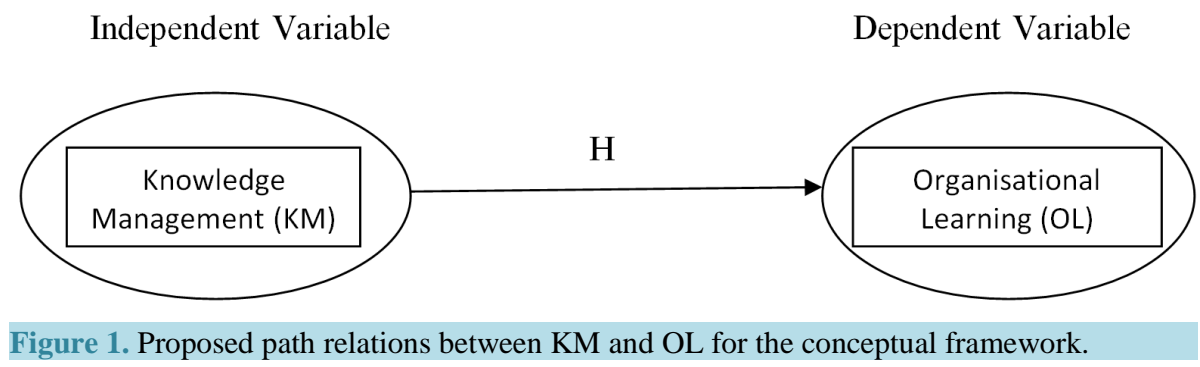




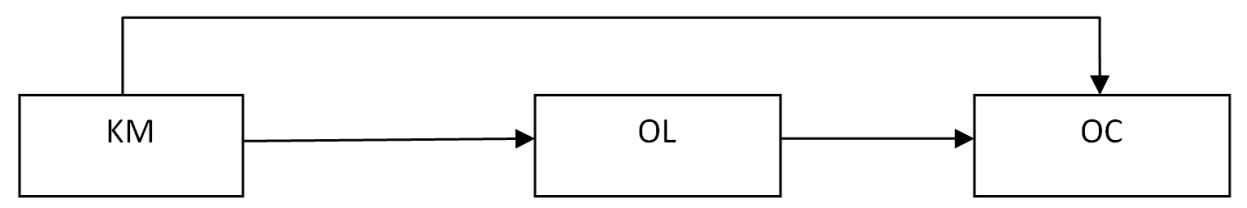

Figure 2. Relation between KM and OC reflecting the influence that is made from OL towards OC to present a holistic model.

structs for OL. The links in the framework projected and predictions are made on the relationship's influence on expected outcomes. Based on the conceptual framework in Figure 1, the study was set to understand the different constructs that need to be investigated. Therefore, the proposed framework and synthesised data outcomes are reviewed to further develop a test to confirm the relationships between the constructs set in the proposed framework. These constructs propose possible practical initiatives that GOs might launch separately or in integration with each other.

In order to measure the Organisational Learning (OL) variable the scales targeted GOs' practices as to make employees feel free to speak their minds about what they have learned. Similarly, part of OL scales focused on the ability of GOs to turn mistakes into constructive learning experiences where it can encourage and cultivate multiple viewpoints of open productive debates. OL scales tried to measure whether the organisation has the ability to break old patterns in order to experiment in different ways of managing daily work, conduct lessons learned sessions, recognize and reward for paradigm breaking solutions to problems, consider learning as an investment than an expense, have interaction sessions that enhance sharing of experiences while setting proper programmes that would close skill gaps and enhance proficiency and manage to involve personnel in important decisions.

\section{Analysis}

\subsection{Introduction}

The analysis of the quantitative data, was taken in stages in order to analyse, review and discuss (Dooley, 2000). The stages in this study were synchronised with the two defined objectives and cross checked for the ability to answer the research question. The following analysis stages were conducted to cover each of the research objectives:

1) Preparatory statistics were established through Missing Values Analysis (MVA) and various psychometrics approaches and procedures were applied in the study.

2) Descriptive statistics were used to describe the main features of the collected data quantitatively and to investigate the specific role of KM in creating OL.

3) Inferential statistics using T-test and One Way ANOVA was used to examine and infer statistical significance for independent samples and the difference between three or more groups, respectively. The inferential test was used to help understand the interactional effects between OL and KM.

4) Pearson's $r$ statistical index was used to describe the degree of strength and the direction of relationship to understand or confirm on which aspects of KM are most influential.

5) Multiple Regression Analysis, Confirmatory Factor Analysis (CFA) and Structural Equation Modelling (SEM) were used for testing and estimating causal relations using a combination of statistical data. This was supported with qualitative causal assumptions to help understand how KM contributes to a holistic approach of organisational development practices that comprises OL.

\subsection{Preparatory Stage-Cleaning and Organizing the Data}

Data collected was checked before, during and after logging for the study integrity and reliability of results, hence the data accuracy was double checked for proper data entry. To avoid distortion of the final results, missing data imputation was conducted. Table 1 shows the missing values for $\mathrm{KM}$ and $\mathrm{OL}$ for $\mathrm{N}=625$. This might be due to the majority of the participants being Department Heads and Directors where sensitivity of data depends on their organisation level of transparency. The interpretation for this is that many participants might have left data entries empty fearing to reveal their identity through completed data, however since the missing values are not above $5 \%$, it was acceptable. There were also up to $2.2 \%$ missing values, when participants were asked 
Table 1. Category of missing values per measured variable, $\mathrm{N}=625$.

\begin{tabular}{ccc}
\hline Category & Missing & \\
\hline & Count & Percent \\
\hline KM & 2 & 0.3 \\
OL & 3 & 0.5 \\
\hline
\end{tabular}

about whether their organisation had a clear process of capturing collective expertise and intelligence. This might be explained again by the fact that participants might not have experienced their government organisation capturing knowledge.

In Table 1 overall missing values are negligible [64].

\subsection{Descriptive Statistics}

For the basic features of the data in the study descriptive statistics were used, to provide simple summaries about the sample and the instrument measures. The researchers distinguished the descriptive statistics from the inferential statistics since the latter is used to reach conclusions that extend beyond the immediate data alone based on the inference about what the population might be thinking; while the use of descriptive statistics is simply to describe what's going on in the research data in terms of percentages, frequencies and distribution. Univariate analysis techniques were used across the cases of one variable at a time, where there are three major characteristics for each single variable intended to be looked at: the distribution, the central tendency, and the dispersion characteristics.

The researchers combined several variables to define the study demographic profile and to generate enough information about the typical organizations, the participants' age, position and how they perceive the organisational learning development practices in their GO (Table 2). The analysis and tables reflect how each particular group of participants perceive the influence of KM on the specific organisational learning development practices.

\subsection{Central Tendency Statistics}

Central tendency analysis is an important part of the descriptive analysis; the analysis was undertaken to estimate the centre of values distribution. This study uses the mean, as compared to the median and the mode; since the mean is found to be the most commonly used method of describing the estimates of the central tendency in the region. The study identifies the dispersion that represents the spread of the values around the central tendency through both the range and the standard deviation of the former shows the result of the highest value minus the lowest value and the set of scores in relation to the mean; respectively.

Most results in Table 3 show the central tendency for the mean and standard deviation to be within (3.5 \pm 0.5$)$; which means that most of the participants perceive their Empirical Research Analysis organisation developments and practices to be high. It is worth noting that some representatives of certain GOs choose an average range of 4 out of 5, meaning they perceive the concepts and practices to be fulfilled. The results propose that (37.4\%) of the participants believe that KM (as an internal resource) is not well utilised. This may be explained by the fact that such managers are not used to seeing areas of improvements. The mean and standard deviation shown in Table 3 are similar in (KM and OL).

\subsection{Inferential Statistics Stage}

In accordance with the data analysis plan the inferential statistics procedure was used to draw inferences about the population from the sample used to estimate a parameter and a confidence interval about the constructed estimate. Inferential statistics was used to detect changes between and within groups; in this research two inferential procedures were used that are the independent samples t-test and the one-way ANOVA.

The t-test in Table 4 reveals that an examination of organisational learning development practices according to gender was not statistically significant at 0.05 . Interestingly to report males' portions were slightly higher than females’ portions with 349 for men and approximately 264/265 for women.

Table 5 examines the size of differences between the age groups for organisation learning development prac- 
Table 2. Demographic table for participants.

\begin{tabular}{cccc}
\hline Category & Sub-Category & Frequency $(\mathrm{N})$ & Percent (\%) \\
\hline \multirow{2}{*}{ Sex } & Male & 350 & 56 \\
& Female & 266 & 43 \\
\hline \multirow{2}{*}{ Age } & Less than 25 & 3 & 0.5 \\
& Between $25-34$ & 177 & 28.3 \\
& $35-45$ & 163 & 26.1 \\
& $46-50$ & 139 & 22.2 \\
\hline \multirow{2}{*}{ Position } & $50+$ & 134 & 21.4 \\
& US & 17 & 2.7 \\
& Manager/Director & 140 & 22.4 \\
& Department Head & 203 & 32.5 \\
\hline
\end{tabular}

Table 3. Mean and Standard Deviation for KM and OL organisation development practices.

\begin{tabular}{cccc}
\hline Organisational Development & Mean & Std. Deviation \\
\hline & Statistic & Std. Error & Statistic \\
\hline Knowledge Management & 3.31 & 0.03 & 0.72 \\
Org Learning & 3.31 & 0.03 & 0.78 \\
\hline
\end{tabular}

Table 4. t-test by gender.

\begin{tabular}{ccccccc}
\hline & Sex & & & Std. & Std. Error & Sig. \\
\cline { 2 - 7 } & & $\mathrm{N}$ & Mean & Deviation & Mean & \\
\hline Knowledge & Male & 349 & 3.2906 & 0.72135 & 0.03861 & 0.875 \\
Management & Female & 265 & 3.3203 & 0.71513 & 0.04393 & 0.152 \\
Org & Male & 349 & 3.3582 & 0.74569 & 0.03922 & 0.04961 \\
Learning & Female & 264 & 3.2204 & 0.80601 & & \\
\hline
\end{tabular}

Table 5. ANOVA differences between age groups.

\begin{tabular}{cccccc}
\hline & & Sum of Squares & Df & Mean Square & Sig. \\
\hline Knowledge & Between Groups & 10.659 & 4 & 2.665 & 5.262 \\
Management & Within Groups & 308.435 & 609 & 0.506 \\
Total & Tetween Groups & 20.119 & 613 & 5.000 \\
Learning & Within Groups & 350.213 & 608 & 0.000 \\
& Total & 370.332 & 612 & & 0.576 \\
\hline
\end{tabular}

tices. Procedure one-way ANOVA was performed on the age data set. The results show that statistical significant difference was obtained for organisational learning development practices. The ANOVA test shows in conclusion that groups do not differ from each other between and within the test variable according to age group variances. 
Table 6 examines the size of differences between the position groups for organisation learning development practices. A procedure one-way ANOVA was performed on the data set. The results show that KM statistically varies according to position groups. The ANOVA test shows that OL does not statistically vary between and within groups according to position.

\subsection{Correlation Analysis}

The results of the correlation coefficients point that participants from top and middle management of GO were consistent in their answers regarding the importance ranking scores of the KM relation with OL. The following sub-sections focus specifically on the correlations of the two main pillars of the study, KM and OC and examine how the defined prevalent organisational learning development practices correlate with them.

\subsection{Organisational Competitiveness Correlations}

As part of the second and third objectives of the study the researchers wanted to determine whether the organisational development practice variable OL influences OC.

The relation between Organisational Learning (OL) and Organisational Competitiveness (OC):

OL-OC showed an overall positive correlation at 0.00 level with $(\mathrm{p}<0.05)$ was $(0.681)$ where the highest correlation among the various indicators of the two dimensions was at (0.494) which existed between the practice of encouragement and cultivation by the organisation for multiple viewpoints and open productive debates correlates (q43) and the analytical capabilities that leads to learning from mistakes (q17). While the lowest correlated coefficient (0.059) was found between conducting Lessons learned sessions (q45) and (q13) creating a good profitable income for government with return on investment, which seemed logical as they are totally from different fields.

The relation between KM and Organisational Learning (OL):

The KM-OL relation showed an overall positive correlation at the 0.00 level $(\mathrm{p}<0.05)$ is $(0.753)$, where the highest correlation among the various indicators of the two dimensions was (0.555) existed between establishing proper programmes that close skill gaps while enhancing proficiency (q49), and managing to have a clear process of capturing the collective expertise and intelligence (q201). The lowest correlated coefficient (0.330) in this relation was found between having (q41) employees feeling free to speak their minds about what they have learned, and (q22) GOs having clearly defined and documented KM strategies; which seemed logical as they are not related to each other. The overall finding from the correlations shows the need for subsequent structural modelling to generalise the KM influence on holistic relations.

\subsection{Regression Analysis and Hypothesis Testing}

Through the regression analysis the hypothesis was tested. The hypothesis went through rigorous tests to see whether the hypothesised relationships can be confirmed or not. The hypothesis proposed a positive association between KM and OL. This hypothesis has been investigated with a linear regression model. The results derived from multiple regression analysis concluded with significant findings. The t-value was more for turning organisation mistakes into constructive learning experiences (q42) than any other indicators. All the indicators determining OL were found to have positive coefficients, except (q43) organization encourages and cultivates multiple viewpoints and open productive debates. Furthermore, a simple regression model examining the influence of

Table 6. ANOVA differences (or similarities) between Position groups.

\begin{tabular}{ccccccc}
\hline & & Sum of Squares & Df & Mean Square & F & Sig. \\
\hline Knowledge & Between Groups & 2.344 & 4 & 0.586 & 1.138 & 0.338 \\
Management & Within Groups & 304.296 & 591 & 0.515 & & \\
& Total & 306.640 & 595 & & & \\
Org & Between Groups & 7.735 & 4 & 1.934 & 3.279 & 0.011 \\
Learning & Within Groups & 347.978 & 590 & 0.590 & & \\
& Total & 355.713 & 594 & & & \\
\hline
\end{tabular}


KM on organisational learning was developed. All indicators in the multiple regression models were significant except (q41) employees feel free to speak their minds about what they have learned and (q43) where the organization encourages and cultivates multiple viewpoints and open productive debates. The results of this simple regression analysis confirm the hypothesised relationship between KM and OL at the 0.05 level.

\section{Discussion of Findings}

The first objective discussing findings related to KM contribution towards the development of organisational learning (OL) practices was addressed. The empirical test of the relations showed a positive correlation between KM-OL which support the research reviewed and thus having a synergy between KM and OL [11] [45] [65] [66]. The result of OL as a set of practices have shown that GOs' employees feel freer to speak their minds on what is learned and hence this would reflect on the ability of the organisation to communicate effectively. Furthermore, the relationship between KM-OL in the set framework raised the possibility of the senior and middle management appreciating their organisations being open for more learning. Further, the results of the OL analysis show that for an organisation to start to turn its mistakes into constructive learning; minimisation of repeated mistakes and staff involvement in certain decisions would help KM practices to occur. Essentially, this can explain why most participants believe that their GOs encourages multiple viewpoints and opens productive debates that lead to building organisational ability to breaking old work style and patterns, and hence move towards organisational innovation practices [67]. The inability of the GOs to benefit from the "lessons learned" sessions does not help promote knowledge sharing experiences. The detailed correlation tables show that most GOs started to adapt OL practices where human capital learning is considered to be more of an investment rather than it being an expense. Furthermore, as the study reveals OL practice seems to be at its early stage since GOs lack proper programmes that close skill gaps and improve proficiency.

The relationship in Figure 3 is established based on the correlation results which reflect the influence of KM practices on OL. From these relations it is now clearer that GOs need to effectively manage knowledge assets to generate new ideas, as observed in Figure 3. That is to say that through effective management of knowledge assets the organisation can both ensure lean services (at best quality, best cost and best delivery) and ensure enhancement of OL practices relevant to analytical capabilities. While managing to have knowledge capturing practices, starting from utilising expertise, would both manage to establish proper programmes that close skill gaps and be able to establish learning programmes that create value in relevance to OL. Therefore, it is concluded in Figure 3 that practices in management of knowledge assets and knowledge capturing need to be established in KM government initiatives.

To meet the first objective an initial conceptual model has been developed to examine the relationships between all the organisational development practices and $\mathrm{KM}$. The following model weas introduced and tested:

$\mathrm{OL}=f(\mathrm{KM}, \mathrm{OC}, \mathrm{OE}, \mathrm{OI}), \mathrm{R}^{2}=0.768$ [OE: Organisational Excellence, OI: Organisational Innnovation].

The model captures the proposed holistic framework depicting progression from KM to OL, and expresses $\mathrm{OL}=f(\mathrm{KM}, \mathrm{OC}, \mathrm{OE}, \mathrm{OI})$ with $\mathrm{R}^{2}=0.768$. $\mathrm{R}^{2}$ represents the amount of variation in the dependent variable which is explained by the model. Thus the holistic model explains $76.8 \%$ of the variation in the dependent suggesting that there might be an area of improvement worth investigating to account for the $23.2 \%$ unexplained variation which could be due to missing variables or interaction among the variables which was not explored.

\section{Conclusions and Future Research}

The findings of this study presented contribute to a better understanding of KM's influence towards GOs competitiveness through Organisational Innovation (OI). Since knowledge assets can be easily duplicated unless external knowledge is integrated with internal knowledge which leads to deliver organizational development prac-

KM influence towards OL

\begin{tabular}{|l|l|}
\hline $\begin{array}{l}\text { Having clear process of capturing } \\
\text { the collective expertise and } \\
\text { intelligence }\end{array}$ & $\begin{array}{l}\text { Establishing proper programmes that } \\
\text { close skill gaps while enhancing } \\
\text { proficiency }\end{array}$ \\
\cline { 2 - 2 }
\end{tabular}

Figure 3. Specific Variable relation that shows Knowledge Management Influence on Organisational Learning. 
tices that lead to better probability of learning performance and organisational values [68]. This reflection is illustrated partly in the framework by the values of organisational excellence, learning, innovation and competitiveness. The framework proposed for this study helps close the gap reflected in the literature about determining whether KM adoption can glue and influence organisational learning and even move organizations towards greater competitiveness.

Research results urge government organisations to recognise KM holistic initiatives as a vehicle for success in creating better organisational development practices and better value. The proposed KM holistic model generates quantitatively better results and exhibits significant relations between KM and the organisational internal resources with Organisational Innovation. This research gives the academic community a new study in KM holistic influence in creating competitive government organisations in the knowledge economy.

The continuation in this field of study would help address GOs' development and success factors such as organisational learning which differentiates such an industry from other sectors [67]. This work supports previous recommendations on the influence of knowledge transfer or KM practices that need to be quantified in order to measure its impact on creating greater citizen satisfaction among GOs [46]. This can support other research as it shows knowledge sharing in GOs enhancing organisational learning and thus can make the GOs' initiatives more customised to specific development practice outcome [36] [69].

An important methodological limitation is the decision to use a quantitative method through a designed questionnaire. Even though this method brought advantages, it also had a drawback in having no normative data available for comparison due to the lack of an empirically validated questionnaire with similar nature questions. The other methodological limitation point is that this research could have produced a more enlightened result by observing the effects of KM implementation on the GOs over a period of time using longitudinal research; which can be an area for future research [70]. This research carries general limitations that most research of this nature and size within the limited scope would go through. The different sizes and variety of the fifty four speciality government organisations in one country limited the possibility of this research generalisation claim, unless it is empirically tested in other countries and regions [71]. This study has opened different possibilities for future research and indicated a number of research directions that would be useful for not only academic researchers, but similarly to the government practitioner. Taking Nonaka's [72] call for not looking at organizations as machines, but living organisms, requires a continuation for the holistic approach towards using and managing knowledge. It is highly recommended from this research to continue investigating other salient variables and/or relations that would complement the model proposed in this study between KM and OI, especially in a turbulent economy and where the need for a holistic approach between the practices of a knowledge economy is still rare in government organisations. One of the important areas which can be taken up by researchers in the course of further study is the establishment of the path flow from KM to OC through OI or any other prevalent organisational development practice. It would be worthwhile for the concept of KM to integrate this research more clearly with newly emerging intellectual capital concepts to see how OL leads to more or less effectiveness towards organisational competitiveness [73]. This type of research outcome should help identify studies relevant to other organisational development as OL.

\section{References}

[1] Chawla, D. and Joshi, H. (2011) Impact of Knowledge Management on Learning Organization Practices in India: An Exploratory Analysis. The Learning Organization, 18, 501-516. http://dx.doi.org/10.1108/09696471111171330

[2] Zheng, W., Yang, B. and McLean, G. (2010) Linking Organizational Culture, Structure, Strategy, and Organizational Effectiveness: Mediating Role of Knowledge Management. Journal of Business Research, 63, 763-771. http://dx.doi.org/10.1016/j.jbusres.2009.06.005

[3] Wiig, K. (2002) Knowledge Management in Public Administration. Journal of Knowledge Management, 6, $224-239$. http://dx.doi.org/10.1108/13673270210434331

[4] Boumarafi, B. and Jabnoun, N. (2008) Knowledge Management and Performance in UAE Business Organisations. Knowledge Management Research and Practice, 6, 233-238. http://dx.doi.org/10.1057/kmrp.2008.16

[5] Al-Alawi, A., Al-Marzooqi, N. and Mohammed, Y. (2007) Organisational Culture and Knowledge Sharing: Critical Success Factors. Journal of Knowledge Management, 11, 22-42. http://dx.doi.org/10.1108/13673270710738898

[6] Haynes, P. (2005) New Development: The Demystification of Knowledge Management for Public Services. Public Money \& Management, 25, 131-135.

[7] Zhi-ze, Z. and Shuang-liang, L. (2012) Government Process Reengineering Based on Knowledge Management. Inter- 
national Conference on E-Business and E-Government (ICEE) 2011, 6-8 May 2012.

[8] Osborne, D. and Gaebler, T. (1992) Reinventing Government. Penguin Group, New York.

[9] Thornhill, S. (2006) Knowledge, Innovation and Firm Performance in High- and Low-Technology Regimes. Journal of Business Venturing, 21, 687-703. http://dx.doi.org/10.1016/j.jbusvent.2005.06.001

[10] Dimitriades, Z. (2005) Creating Strategic Capabilities: Organizational Learning and Knowledge Management in the New Economy. European Business Review, 17, 314-324. http://dx.doi.org/10.1108/09555340510607361

[11] Liao, S. and Wu, C. (2009) The Relationship among Knowledge Management, Organisational Learning, and Organisational Performance. International Journal of Business and Management, 4, 64-76. http://dx.doi.org/10.5539/ijbm.v4n4p64

[12] Morales, V., Montesa, F. and Joverb, A. (2007) Influence of Personal Mastery on Organizational Performance through Organizational Learning and Innovation in Large Firms and SMEs. Technovation, 27, 547-568. http://dx.doi.org/10.1016/j.technovation.2007.02.013

[13] Rusly, F., Corner, J. and Sun, P. (2012) Positioning Change Readiness in Knowledge Management Research. Journal of Knowledge Management, 16, 329-355. http://dx.doi.org/10.1108/13673271211218906

[14] Aranda, D. and Fernandez, L. (2002) Determinants of Innovation through a Knowledge-Based Theory Lens. Industrial Management and Data Systems, 102, 289-296. http://dx.doi.org/10.1108/02635570210428320

[15] Akdere, M. (2009) The Role of Knowledge Management in Quality Management Practices: Achieving Performance Excellence in Organisations. Advances in Developing Human Resources, 11, 349-361. http://dx.doi.org/10.1177/1523422309338575

[16] Burke, M. (2011) Knowledge Sharing in Emerging Economies. Library Review, 60, 5-14. http://dx.doi.org/10.1108/00242531111100531

[17] Gorry, G. (2008) Sharing Knowledge in the Public Sector: Two Case Studies. Knowledge Management Research and Practice, 6, 105-111. http://dx.doi.org/10.1057/palgrave.kmrp.8500172

[18] McAdam, R. and Reid, R. (2000) A Comparison of Public and Private Sector Perceptions and Use of Knowledge Management. Journal of European Industrial Training, 24, 317-329. http://dx.doi.org/10.1108/03090590010346424

[19] Hlupic, V., Pouloudi, A. and Rzevski, G. (2002) Towards an Integrated Approach to Knowledge Management: "Hard”, "Soft" and "Abstract" Issues. Knowledge and Process Management, The Journal of Corporate Transformation, 9, 90-102.

[20] Raadschelders, J. (2005) Government and Public Administration: Challengers to an Need for Connection. Administrative Theory and Praxis, 27, 602-627.

[21] Handzic, M. (2011) Integrated Socio-Technical Knowledge Management Model: An Empirical Evaluation. Journal of Knowledge Management, 15, 198-211. http://dx.doi.org/10.1108/13673271111119655

[22] Kasim, R. (2008) The Relationship of Knowledge Management Practices, Competencies and the Organizational Performance of Government, Departments in Malaysia. Proceedings of World Academy of Science, Engineering and Technology, 36, 798-804.

[23] Abbass, F., Hayat, M., Shahzad, A. and Riaz, A. (2011) Analysis of Knowledge Management in the Public Sector of Pakistan. European Journal of Social Sciences, 19, 471-478.

[24] Sotirakou, T. and Zeppou, M. (2004) The "MATE” Model: A Strategic Knowledge Management Technique on the Chessboard of Public-Sector Modernization. Management Decision, 42, 69-88. http://dx.doi.org/10.1108/00251740410504430

[25] Syed-Ikhsan, S.M. and Rowland, F. (2004) Knowledge Management in a Public Organisation: A Study between the Relationship of the Organisational Elements and the Performance of Knowledge Transfer. Journal of Knowledge Management, 8, 95-111. http://dx.doi.org/10.1108/13673270410529145

[26] Connelly, C., Zweig, D., Webster, J. and Trougakos, J. (2012) Knowledge Hiding in Organizations. Journal of Organizational Behaviour, 33, 64-88. http://dx.doi.org/10.1002/job.737

[27] Riege, A. and Lindsay, N. (2006) Knowledge Management in the Public Sector: Stakeholder Partnerships in the Public Policy Development. Journal of Knowledge Management, 10, 24-39. http://dx.doi.org/10.1108/13673270610670830

[28] Chan, K. and Liebowitz, J. (2006) The Synergy of Social Network Analysis and Knowledge Mapping: A Case Study. International Journal of Management and Decision Making, 7, 19-35. http://dx.doi.org/10.1504/IJMDM.2006.008169

[29] Gore, A. (1996) Creating a Government that Works Better and Costs Less: Report of the National Performance Review. U.S. Government Print Office, Washington DC.

[30] Senge, P. (1990) The Fifth Discipline: The Art and Practice of the Learning Organisation. Doubleday, New York.

[31] Martin, W.J. (2004) Demonstrating Knowledge Value: A Broader Perspective on Metrics. Journal of Intellectual 
Capital, 5, 77-91. http://dx.doi.org/10.1108/14691930410512932

[32] Venkitachalam, K. and Busch, P. (2012) Tacit Knowledge: Review and Possible Research Directions. Journal of Knowledge Management, 16, 357-372. http://dx.doi.org/10.1108/13673271211218915

[33] Lee, S., Kim, B. and Kim, H. (2012) An Integrated View of Knowledge Management for Performance. Journal of Knowledge Management, 16, 183-203. http://dx.doi.org/10.1108/13673271211218807

[34] Firestone, J. and McElroy, M. (2004) Organizational Learning and Knowledge Management: The Relationship. The Learning Organization, 11, 177-184. http://dx.doi.org/10.1108/09696470410521628

[35] Maden, C. (2012) Transforming Public Organizations into Learning Organizations: A Conceptual Model. Public Organization Review, 12, 71-84. http://dx.doi.org/10.1007/s11115-011-0160-9

[36] Lundvall, B. and Nielsen, P. (2007) Knowledge Management and Innovation Performance. International Journal of Manpower, 28, 207-223. http://dx.doi.org/10.1108/01437720710755218

[37] Lee, H. and Choi, B. (2003) Knowledge Management Enablers, Processes and Organisational Performance: An Integrative View and Empirical Examination. Journal of Management Information Systems, 20, 179-228.

[38] Singh, S. (2008) Role of Leadership in Knowledge Management: A Study. Journal of Knowledge Management, 12, 3-15. http://dx.doi.org/10.1108/13673270810884219

[39] Basadur, M. and Gelade, G. (2006) The Role of Knowledge Management in the Innovation Process. Creativity and Innovation Management, 15, 45-62. http://dx.doi.org/10.1111/j.1467-8691.2006.00368.x

[40] Njuguna, J. (2009) Strategic Positioning for Sustainable Competitive Advantage: An Organisational Learning Approach. KCA Journal of Business Management, 2, 32-43.

[41] Moffett, S., McAdam, R. and Parkinson, S. (2003) An Empirical Analysis of Knowledge Management Applications. Journal of Knowledge Management, 7, 6-26. http://dx.doi.org/10.1108/13673270310485596

[42] Hughes, P., Morgan, R. and Kouropalatis, Y. (2008) Market Knowledge Diffusion and Business Performance. European Journal of Marketing, 42, 1372-1395. http://dx.doi.org/10.1108/03090560810903718

[43] Tseng, S. (2010) The Correlation between Organizational Culture and Knowledge Conversion on Corporate Performance. Journal of Knowledge Management, 14, 269-284. http://dx.doi.org/10.1108/13673271011032409

[44] Rhodes, J., Hung, R., Lok, P., Ya-Hui Lien, B. and Wu, C. (2008) Factors Influencing Organisational Knowledge transfer: Implication for Corporate Performance. Journal of Knowledge Management, 12, 84-100. http://dx.doi.org/10.1108/13673270810875886

[45] Chinowsky, P. and Carrillo, P. (2007) Knowledge Management to Learning Organisation Connection. Journal of Management in Engineering, 23, 122-130. http://dx.doi.org/10.1061/(ASCE)0742-597X(2007)23:3(122)

[46] Goh, S. (2002) Managing Effective Knowledge Transfer: An Integrative Framework and Some Practice Implications. Journal of Knowledge Management, 6, 23-30. http://dx.doi.org/10.1108/13673270210417664

[47] Grant, R. (1996) Toward a Knowledge-Based Theory of the Firm. Strategic Management Journal, 17, 109-122. http://dx.doi.org/10.1002/smj.4250171110

[48] Eskildsen, J., Dahlgaard, J. and Norgaard, A. (1999) The Impact of Creativity and Learning on Business Excellence. Total Quality Management, 10, 523-530. http://dx.doi.org/10.1080/0954412997488

[49] Yahya, S. and Goh, W. (2002) Managing Human Resources towards Achieving Knowledge Management. Journal of Knowledge Management, 6, 457-468. http://dx.doi.org/10.1108/13673270210450414

[50] Hwang, A. (2003) Training Strategies in the Management of Knowledge. Journal of Knowledge Management, 7, 92104.

[51] Harvey, R. and Hider, P. (2004) Organising Knowledge in a Global Society. Centre for Information Studies, Wagga Wagga.

[52] Massingham, P. and Diment, K. (2009) Organizational Commitment, Knowledge Management Interventions, and Learning Organization Capacity. The Learning Organization, 16, 122-142. http://dx.doi.org/10.1108/09696470910939206

[53] Bishop, J., Bouchlaghem, D., Glass, J. and Matsumoto, I. (2008) Ensuring the Effectiveness of a Knowledge Management Initiative. Journal of Knowledge Management, 12, 16-29. http://dx.doi.org/10.1108/13673270810884228

[54] Fugate, B., Stank, T. and Mentzer, J. (2009) Linking Improved Knowledge Management to Operational and Organizational Performance. Journal of Operations Management, 27, 247-264. http://dx.doi.org/10.1016/j.jom.2008.09.003

[55] Castilla, J. and Ruiz, O. (2008) EFQM Model: Knowledge Governance and Competitive Advantage. Journal of Intellectual Capital, 9, 133-156. http://dx.doi.org/10.1108/14691930810845858

[56] Dooley, D. (2000) Social Research Methods. 4th Edition, Prentice-Hall Publishing, New Jersey. 
[57] Yang, H. (2008) Managing Knowledge for Quality Assurance: An Empirical Study. International Journal of Quality and Reliability Management, 25, 109-124. http://dx.doi.org/10.1108/02656710810846907

[58] Migdadi, M. (2005) An Integrative View and Empirical Examination of the Relationships among Knowledge Management Practices, Processes, and Organisational Performance in Australian Enterprises. Ph.D. Thesis, University of Wollongog, Wollongong.

[59] Al-Busaidi, K. and Olfman, L. (2005) An Investigation of the Determinants of Knowledge Management Systems Success in Omani Organisations. Journal of Global Information Technology Management, 8, 6-27. http://dx.doi.org/10.1080/1097198X.2005.10856400

[60] Creswell, J.W. (2003) Research Design: Quantitative, Qualitative, and Mixed Methods Approaches. 2nd Edition, Sage, Thousand Oaks.

[61] Davenport, T.H. and Prusak, L. (2000) Working Knowledge: How Organisations Manage What They Know. Harvard Business School Press, Boston.

[62] Malhotra, Y. (2005) Integrating Knowledge Management Technologies in Organisational Business Processes: Getting Real Time Enterprises to Deliver Real Business Performance. Journal of Knowledge Management, 9, 7-28. http://dx.doi.org/10.1108/13673270510582938

[63] Pun, K. and Balkissoon, M. (2011) Integrating Knowledge Management into Organisational Learning: A Review of Concepts and Models. The Learning Organization, 18, 203-223. http://dx.doi.org/10.1108/09696471111123261

[64] Lee, W., Hung, S. and Chau, P. (2011) Influence of Knowledge Management Infrastructure on Innovative Business Processes and Market-Interrelationship Performance: An Empirical Study of Hospitals in Taiwan. Journal of Global Information Management, 19, 67-89. http://dx.doi.org/10.4018/jgim.2011040104

[65] Ho, L. (2008) What Affects Organisational Performance? The Linking of Learning and Knowledge Management. Industrial Management and Data Systems, 108, 1234-1254. http://dx.doi.org/10.1108/02635570810914919

[66] Loermans, J. (2002) Synergizing the Learning Organisation and Knowledge Management. Journal of Knowledge Management, 6, 285-294. http://dx.doi.org/10.1108/13673270210434386

[67] Weerawardena, J., O’Cass, A. and Julian, C. (2006) Does Industry Matter? Examining the Role of Industry Structure and Organizational Learning in Innovation and Brand Performance. Journal of Business Research, 59, 37-45. http://dx.doi.org/10.1016/j.jbusres.2005.02.004

[68] Phusavat, K., Anussornnitisarn, P., Patthananurak, P., Kekale, T. and Helo, P. (2010) Sustaining Organisational Development through Knowledge Management in the Public Sector. International Journal of Sustainable Economy, 2, 16-31. http://dx.doi.org/10.1504/IJSE.2010.029939

[69] Lin, H. (2007) Knowledge Sharing and Firm Innovation Capability: An Empirical Study. International Journal of Manpower, 28, 315-332. http://dx.doi.org/10.1108/01437720710755272

[70] De Vaus, D. (2002) Surveys in Social Research. 5th Edition, Routledge, London.

[71] Neuman, W. (2003) Social Research Methods: Qualitative and Quantitative Approaches. 5th Edition, Allan and Bacon, Boston.

[72] Nonaka, I. (1998) The Knowledge-Creating Company. Harvard Business Review on Knowledge Management. Harvard Business School Publishing, Boston, 21-45.

[73] Hsu, I. (2008) Knowledge Sharing Practices as a Facilitating Factor for Improving Organizational Performance through Human Capital: A Preliminary Test. Expert Systems with Applications, 35, 1316-1326.

http://dx.doi.org/10.1016/j.eswa.2007.08.012 
Scientific Research Publishing (SCIRP) is one of the largest Open Access journal publishers. It is currently publishing more than 200 open access, online, peer-reviewed journals covering a wide range of academic disciplines. SCIRP serves the worldwide academic communities and contributes to the progress and application of science with its publication.

Other selected journals from SCIRP are listed as below. Submit your manuscript to us via either submit@scirp.org or Online Submission Portal.
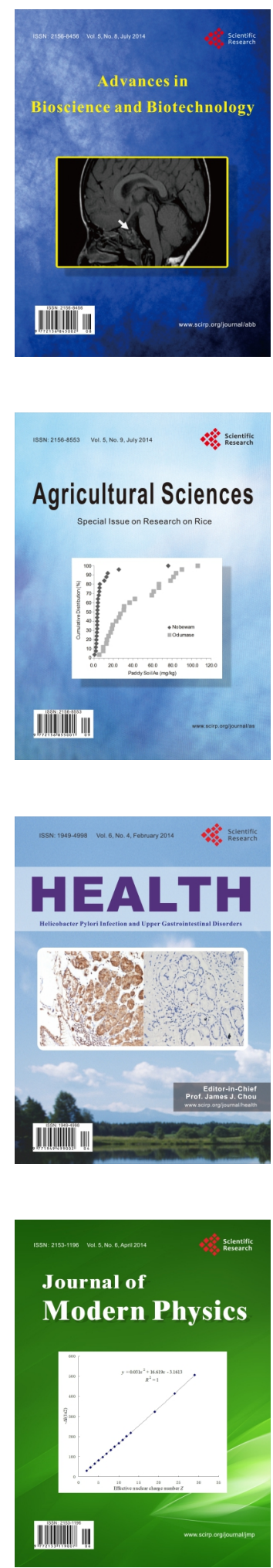
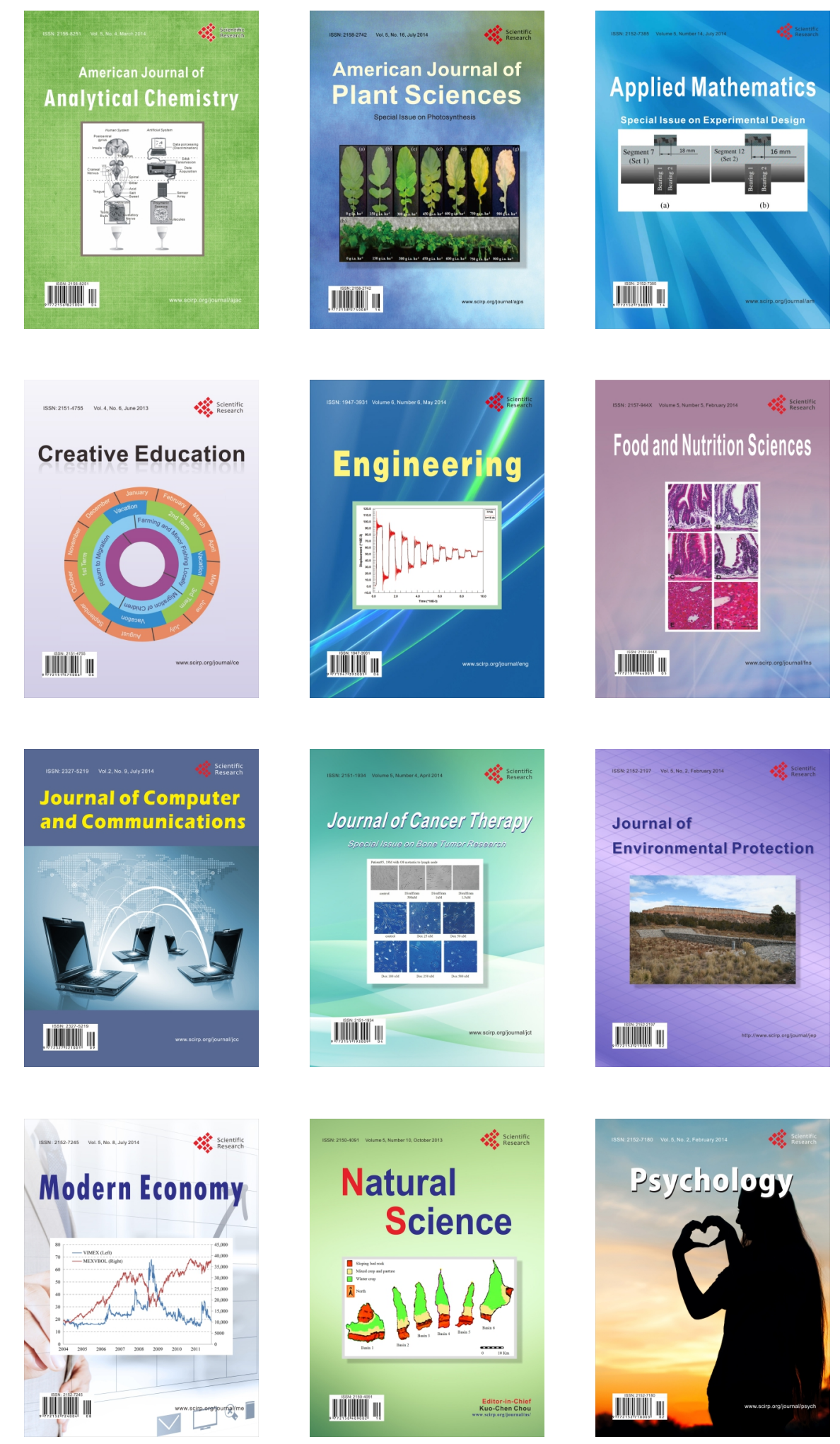